\title{
Environmental factors and risk of delirium in geriatric patients: an observational study
}

Sigurd Evensen ${ }^{1,2^{*}} \mathbb{D}$, Ingvild Saltvedt ${ }^{1,2}$, Stian Lydersen ${ }^{3}$, Torgeir Bruun Wyller ${ }^{4,5}$, Kristin Taraldsen $^{2}$ and Olav Sletvold ${ }^{1,2}$

\begin{abstract}
Background: Patients with delirium have increased risk of death, dementia and institutionalization, and prognosis differs between delirium motor subtypes. A few studies have identified associations between environmental factors like room-transfers and time spent in the emergency department (ED) and delirium, but no studies have investigated if environmental factors may influence delirium motor subtypes. We wanted to explore if potentially stressful events like ward-transfers, arriving ED at nighttime, time spent in ED and nigthttime investigations were associated with development of delirium (incident delirium) and delirium motor subtypes.
\end{abstract}

Methods: We used the DSM-5 criteria to diagnose delirium and the Delirium Motor Subtype Scale for motor subtyping. We defined hyperactive and mixed delirium as delirium with hyperactive symptoms, and hypoactive and no-subtype delirium as delirium without hyperactive symptoms. We registered ward-transfers, time of arrival in ED, time spent in ED and nighttime investigations (8 p.m. to 8 a.m.), and calculated Global Deterioration Scale (GDS) and Cumulative Illness Rating Scale (CIRS) to adjust for cognitive impairment and comorbidity. We used logistic regression analyses with incident delirium and delirium with hyperactive symptoms as outcome variables, and ward-transfers, arriving ED at nighttime, time spent in ED and nighttime investigations as exposure variables, adjusting for age, GDS and CIRS in the analyses for incident delirium.

Results: We included 254 patients, mean age 86.1 years (SD 5.2), 49 (19.3\%) had incident delirium, 22 with and 27 without hyperactive symptoms. There was a significant association between nighttime investigations and incident delirium in both the unadjusted (odds ratio (OR) 2.22, 95\% confidence interval (Cl) 1.17 to 4.22, $p=0.015)$ and the multiadjusted model (OR 2.61, Cl 1.26 to 5.40, $p=0.010$ ). There were no associations between any other exposure variables and incident delirium. No exposure variables were associated with delirium motor subtypes.

Conclusions: Nighttime investigations were associated with incident delirium, even after adjusting for age, cognitive impairment and comorbidity. We cannot out rule that the medical condition leading to nighttime investigations is the true delirium-trigger, so geriatric patients must still receive emergency investigations at nighttime. Hospital environment in broad sense may be a target for delirium prevention.

Keywords: Delirium, Risk factors, Geriatric patients, Hospital, Environmental

\footnotetext{
* Correspondence: sigurd.evensen@ntnu.no

${ }^{1}$ Department of Geriatrics, St. Olavs hospital, Trondheim University Hospital, Trondheim, Norway

${ }^{2}$ Department of Neuromedicine and Movement Science, Faculty of Medicine and Health Sciences, Norwegian University of Science and Technology (NTNU), N-7491 Trondheim, Norway

Full list of author information is available at the end of the article
}

(c) The Author(s). 2018 Open Access This article is distributed under the terms of the Creative Commons Attribution 4.0 International License (http://creativecommons.org/licenses/by/4.0/), which permits unrestricted use, distribution, and reproduction in any medium, provided you give appropriate credit to the original author(s) and the source, provide a link to the Creative Commons license, and indicate if changes were made. The Creative Commons Public Domain Dedication waiver (http://creativecommons.org/publicdomain/zero/1.0/) applies to the data made available in this article, unless otherwise stated. 


\section{Background}

Delirium is an acute disturbance of attention, awareness and cognition, affecting one third of older medical inpatients [1]. High age, cognitive impairment and comorbidity are the most important risk factors [2]. Patients suffering from delirium have increased risk of death, cognitive impairment and institutionalization [3], and delirium has substantial medical, societal and economical implications on the entire health care system [4]. Four different motor subtypes of delirium have been described; hyperactive delirium, hypoactive delirium, mixed delirium with both hyperactive and hypoactive features and no-subtype delirium without motor disturbances [5]. Most studies find that hypoactive delirium has worst prognosis [5-9]. It is unclear whether risk factors and etiology differ between motor subtypes $[8,10,11]$.

The Diagnostic and Statistical Manual of Mental Disorders (DSM-5) criteria [12] are physiologically oriented and state that delirium is caused by medical conditions, substance intoxication or withdrawal, exposure to a toxin, or is due to multiple etiologies. On the other hand, nonpharmacological intervention programs focusing on activity, orientation and sleep hygiene are effective to prevent delirium [13, 14], indicating that environmental factors may have a role in development of delirium. There are previous reports on both sensory deprivation [15] and sensory overload [16] as contributors to delirium, and three studies have identified associations between specific environmental factors in the hospital care pathway and delirium. Goldberg et al. and Bo et al. found associations between room-transfers and time spent in the emergency department (ED) and development of delirium, respectively $[17,18]$, and McCusker et al. found that increasing number of room-transfers increased the severity of delirium [15]. These associations seem plausible since both room-transfers and long time spent in ED can be stressfull events that might be able to induce aberrant stress responses eventually contributing to delirium [19]. To our knowledge, no studies have investigated the association between environmental factors and motor subtypes of delirium, which is of interest since the motor subtypes have different prognosis.

Due to the substantial impact of delirium and the increasing number of delirium-prone older patients in strained and crowded hospitals [20], there is a need to further explore the associations between potentially stressful environmental factors in the hospital care patway and delirium. The aim of this study is to specifically investigate if ward-transfers, arriving ED at nighttime, time spent in ED and visits from other specialists and radiological procedures at nighttime (nighttime investigations) are associated with development of delirium (incident delirium) and delirium motor subtypes in patients acutely admitted to a geriatric ward.

\section{Methods}

\section{Design, settings and participants}

This is a prospective observational study conducted at the medical geriatric ward at St. Olavs hospital, Trondheim University Hospital, Norway, between May 62015 and January 31 2017. The ward has 15 single-bed rooms, and the patients receive comprehensive geriatric assessment and care [21] by an interdisciplinary geriatric team consisting of physicians, nurses, occupational therapists and physiotherapists. Ninety per cent of the patients are acutely admitted with conditions like infections, injuries after falls, cardiopulmonary conditions and dehydration [22]. Acutely admitted patients arrive via the ED which has ten regular rooms, three acute-rooms and eight beds in a triage room. Nurses collect blood-samples in the ED. Physicians examine the patients in the ED before the patients as soon as possible are transferred to a relevant ward. The patients frequently receive radiological procedures during transfer between ED and the ward. As in other hospitals [20], the ED is frequently chaotic and over-crowded.

The inclusion criteria were age $\geq 75$ years and acute admittance. Patients transferred from other wards were eligible for inclusion if they met the inclusion criteria. We excluded patients previously taking part in the study and patients with delirium on admittance. Nurses, physiotherapists or a physician (SE) included all patients within $24 \mathrm{~h}$ after arriving the ward.

\section{Diagnosis of delirium and delirium motor subtypes}

We diagnosed delirium according to the DSM-5 criteria, judging consciousness, awareness and arousal clinically, testing attention using the digit span forwards and backwards [23] and cognitive impairment using the ten orientation items and the three word short time memory test from the Mini Mental Status Excamination [24]. In this population of elderly patients we particularily stressed that the present symptoms could not be better explained by preexisting dementia and that the delirium episode had to be a consequence of physiological disturbances. We based the final diagnosis on all available information, i.e. first day visits to all patients, interviews with nurses and proxies and careful chart review as described by Inouye [25], since this combined approach increases the number of patients correctly diagnosed with delirium [26]. When in doubt concerning the diagnosis, and if the staff noticed changes in mental status, we visited the patient several times.

After diagnosing delirium, we did motor subtyping using the Delirium Motor Subtype Scale (DMSS) [27]. The DMSS lists four hyperactive and seven hypoactive features. To fulfill the criteria for a certain motor subtype, the patient must have at least two of these features. Patients having both hyperactive and hypoactive features 
get the diagnosis of mixed delirium, and patients with one or less motor feature get the diagnosis of no-subtype delirium. Due to a small number of observations, we combined the patients with hyperactive and mixed delirium to create the category "delirium with hyperactive symptoms" and the patients with hypoactive and no-subtype delirium to create the category "delirium without hyperactive symptoms." In patients not visited due to logistical reasons, we based the diagnosis of delirium and motor subtype on careful chart review. We were not able to secure that the delirium assessors were completely blinded to exposure status of environmental factors.

\section{Data collection}

We registered time of arrival at the ED and total time in the ED retrospectively using the hospital's ED database. We defined nighttime between 8 p.m. and 8 a.m. We registered cerebral MRI-scans, other radiological investigations (CT-scans, ultrasound and $\mathrm{x}$-rays) and visits from other specialties at nighttime retrospectively reviewing the hospital records. Due to small numbers of cerebral MRI-scans and visits from other specialties we combined these with other radiological investigations and created the category investigations at nighttime, despite that MRI-scans might be a stronger contributor to incident delirium due to noise and narrowness. Nurses registered ward-transfers consecutively (yes/no).

To be able to adjust for cognitive impairment, we scored the Global Deterioration Scale (GDS) [28]. The GDS ranges from one to seven, one indicates no cognitive symptoms, seven indicates end-stage dementia. We defined dementia as a GDS-score more than four. To be able to adjust for comorbidity, we calculated the Cumulative Illness Rating Scale (CIRS) retrospectively reviewing the hospital records [29]. CIRS ranges from 0 to 56; higher score indicates increasing comorbidity.

We used the Barthel Index (BI, 0 to 20, 20 best score) as a baseline measure of personal Activities of Daily Living [30] prior to hospitalization and the Short Physical Performance Battery (SPPB, 0 to 12, 12 best score) as a baseline measure of general health and frailty [31]. We used a modified APACHE II-score (0 to 71, increasing score indicates more severe illness) as a baseline measure of acute illness [32]. We collected demographic data from the hospital records.

\section{Ethics}

The Regional Committee for Medical and Health Research Ethics of Mid-Norway approved the study (REC Central 2015/474). Since there were no elements of invasive or uncomfortable procedures, the patients could consent for participation even if they had signs of cognitive impairment. If the patient was unable to give consent, a proxy could sign the consent form. Independent of cognitive status, we never included patients who expressed concerns about participation.

\section{Statistical analysis}

We present descriptive data for continuous variables as means and standard deviations (SD), and for dichotomous and categorical variables as percentages. To investigate if the exposure variables ward-transfers, arrival at nighttime, time spent in ED and nighttime investigations were associated with incident delirium, we used logistic regression analyses, unadjusted and multiadjusted, with incident delirium as outcome variable. To adjust for important risk factors for delirium we also included the covariates age, GDS (cognitive function) and CIRS (comorbidity) in the analyses. We used the same strategy to study the relation between the exposure variables and motor subtypes, using incident delirium with hyperactive symptoms as outcome variable. Due to a small numbers of observations, we did not include the covariates age, GDS and CIRS in the latter analysis. This study is part of a project where the main aim was to detect differences in one-year mortality between patients with hypoactive and hyperactive delirium, and we based power calculation on an assumption of $50 \%$ mortality among 60 patients with hypoactive delirium and $20 \%$ mortality among 40 patients with hyperactive delirium, giving a power of $87.9 \%$ with $\alpha=0.05$. We report odds ratios (OR) with 95\% confidence intervals (CI) from the logistic regression analyses and judge two-sided $p$-values $<0.05$ as statistically significant. We completed all analyses using SPSS version 25.

\section{Results}

In total, 311 patients took part in the study. After reviewing the medical notes from the $\mathrm{ED}$ and other wards, we excluded 54 patients with delirium on admittance. As illustrated in Fig. 1 we excluded one patient who died the night of inclusion and two patients who were discharged the next day. This article thus reports analyses of 254 patients. As shown in Table 1, mean age was 86.1 years (SD 5.2), 151 (58.4\%) were female and 133 (52.4\%) had dementia.

Fourty-nine patients had incident delirium, of which we diagnosed 41 through direct assessment by the first author and the remaining eight through chart review. Eleven had hyperactive delirium, 11 mixed delirium, 18 hypoactive delirium and nine had no-subtype delirium. Thus, 22 patients had delirium with hyperactive symptoms and 27 had delirium without hyperactive symptoms. Regarding exposure variables, 42 out of 254 patients $(16.5 \%)$ were transferred from other wards, 44 (17.3\%) arrived at nighttime and 77 (30.3\%) received 


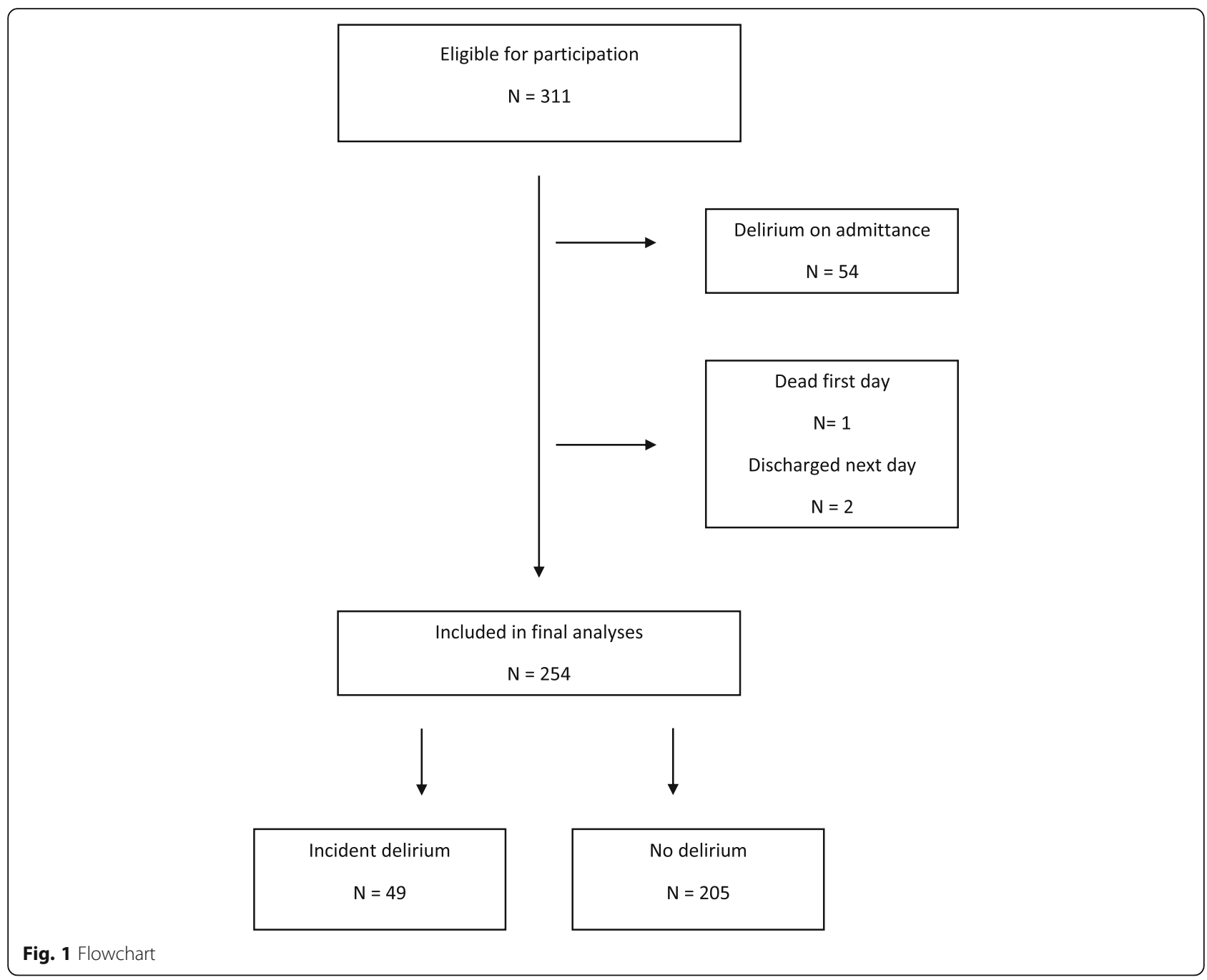

Table 1 Baseline characteristics for all patients, patients with incident delirium and patients remaining free of delirium

\begin{tabular}{|c|c|c|c|c|}
\hline & $\begin{array}{l}\text { All (254) } \\
\text { Mean; SD }\end{array}$ & $\begin{array}{l}\text { Incident delirium }(n=49) \\
\text { Mean; SD }\end{array}$ & $\begin{array}{l}\text { No delirium }(n=205) \\
\text { Mean; SD }\end{array}$ & $p$-values ${ }^{2}$ \\
\hline Age (years) & $86.1 ; 5.2$ & $86.9 ; 5.0$ & $85.8 ; 5.2$ & 0.20 \\
\hline Body Mass Index & $24.2 ; 4.3$ & $23.4 ; 3.6$ & $24.4 ; 4.4$ & 0.12 \\
\hline GDS $^{b}(1-7)$ & $3.4 ; 1.7$ & $4.3 ; 1.3$ & 3.2: 1.7 & $<0.001$ \\
\hline $\mathrm{CIRS}^{\mathrm{C}}(0-56)$ & $12.9 ; 4.4$ & $14.3 ; 4.6$ & $12.6 ; 4.3$ & 0.020 \\
\hline APACHE (0-71) & $8.9 ; 2.7$ & $9.3 ; 2.7$ & $8.8 ; 2.7$ & 0.30 \\
\hline Barthel Index (0-20) & $16.3 ; 3.6$ & $14.9 ; 4.0$ & $16.7 ; 3.4$ & 0.002 \\
\hline $\operatorname{SPPB}^{\mathrm{d}}(0-12)$ & $4.0 ; 3.0$ & $2.5 ; 2.6$ & $4.3 ; 3.1$ & $<0.001$ \\
\hline Female & $151(59.4 \%)$ & $23(46.9 \%)$ & $128(62.4 \%)$ & 0.049 \\
\hline Home-dwelling & 246 (96.9\%) & $46(93.9 \%)$ & $200(97.6 \%)$ & 0.19 \\
\hline Dementia (GDS > 4) & 133 (52.4\%) & 38 (77.6\%) & 95 (46.3\%) & $<0.001$ \\
\hline
\end{tabular}

Baseline characteristics for all patients, patients with incident delirium and patients remaining free of delirium

${ }^{\mathrm{b}}$ Global Deterioration Scale

${ }^{c}$ Cumulative Illness Rating Scale

${ }^{\mathrm{d}}$ Short Physical Performance Battery 
nighttime investigations of which three had cerebral MRI-scans, 65 other radiological investigations and nine received visits from other specialities. Those arriving at nighttime received 25 (32.5\%) of the nighttime investigations. The mean time spent in ED was 4.1 h (SD 0.9).

Table 2 and Table 3 show results of the logistic regression analyses. In the unadjusted model, nighttime investigations were significantly associated with incident delirium (OR 2.22, CI 1.17 to 4.22, $p=0.015$ ), indicating a more than doubled risk of incident delirium if the patient was exposed to nighttime investigations. In the multiadjusted model, nighttime investigations remained significantly associated with incident delirium (OR 2.61, CI 1.26 to $5.40, p=0.010$ ). Figure 2 illustrates the associations between ward-transfers, arriving at nighttime, nighttime investigations, time spent in ED and incident delirium. There were no significant associations between any of the exposure variables and the two groups of delirium motor subtypes.

\section{Discussion}

In this observational study in acutely admitted geriatric patients, there was a significantly increased risk of incident delirium associated with exposure to nighttime investigations, even after adjusting for age, cognitive impairment and comorbidity, all well-known risk factors for delirium. There were no significant associations between ward-transfers, arrival at nighttime, time spent in ED and incident delirium. There were no associations between any of the exposure variables and delirium motor subtypes.

Previous studies have identified associations between room-transfers $[15,17]$ and time spent in ED [18] and delirium. These previous findings as well as our result seem biologically plausible since both room-transfers, long time spent in ED and nighttime investigations are potentially stressfull events that could induce aberrant stress responses which is a widely held hypothesis [19] regarding the pathophysiology of delirium. On the other hand, the association between nighttime investigations and incident delirium might be a spurious finding since the medical condition leading to nighttime investigations might be the true trigger of delirium, and not the investigation itself. The uncertainty about what is the true delirium trigger could have been reduced if we had reliable admission diagnoses, but in our opinion diagnoses on admission forms, at least in our hospital, are too unreliable to be used for this purpose. Like all observational studies, our study is unable to establish firm causality, and our findings must not be overinterpreted. In our opinion, clinicians must still refer geriatric patients to medically indicated nighttime investigations, but hospital organizers should secure that non-emergency investigations are done in a predictable way at daytime.

These associations between environmental factors and delirium are supported by studies showing that nonpharmacological, mainly environmental intervention programs are effective in preventing delirium [13, 14, 33]. Since delirium is common [1], has poor prognosis [3] and substantial economical impact [2], there seems to be a large potential for both health-related and economical benefits through focus on hospital environment and implementation of non-pharmacological delirium intervention programs. Such interventions also seem to have benefits beyond delirium prevention. In addition to a $44 \%$ reduction in delirium incidence, a meta-analysis from 2015 reports a $64 \%$ reduction in fall rates and a trend towards reduced length of stay and institutionalization rates in the intervention groups [13].

We found no association between ward-transfers and incident delirium. A possible explanation is that all wardtransfers are done in a predictable way at daytime. Another explanation may be that the geriatric ward provides a multicomponent intervention program against delirium that may out-weigh the potentially negative effect of ward-transfers. If so, this effect could also have influenced

Table 2 Logistic regression analyses with incident delirium $(n=49)$ as outcome variable, unadjusted and multiadjusted, for all the listed covariates, for all 254 patients

\begin{tabular}{|c|c|c|c|c|c|c|}
\hline & \multicolumn{3}{|c|}{ Unadjusted } & \multicolumn{3}{|c|}{ Multiadjusted } \\
\hline & OR & $95 \% \mathrm{Cl}$ & $p$-value & OR & $95 \% \mathrm{Cl}$ & $p$-value \\
\hline Ward-transfers & 0.98 & 0.42 to 2.28 & 0.97 & 0.70 & 0.28 to 1.72 & 0.43 \\
\hline Arrive late $^{a}$ & 0.76 & 0.32 to 1.82 & 0.53 & 0.56 & 0.20 to 1.55 & 0.26 \\
\hline Time spent in ED (hours) & 0.89 & 0.75 to 1.06 & 0.20 & 0.85 & 0.69 to 1.04 & 0.12 \\
\hline Investigations at nighttime $e^{a}$ & 2.22 & 1.17 to 4.22 & 0.015 & 2.61 & 1.26 to 5.40 & 0.010 \\
\hline Age (years) & 1.04 & 0.98 to 1.11 & 0.20 & 1.03 & 0.97 to 1.10 & 0.37 \\
\hline $\mathrm{GDS}^{\mathrm{b}}$ & 1.54 & 1.24 to 1.91 & $<0.001$ & 1.59 & 1.26 to 1.99 & $<0.001$ \\
\hline $\mathrm{CIRS}^{\mathrm{C}}$ & 1.09 & 1.01 to 1.17 & 0.020 & 1.08 & 1.00 to 1.18 & 0.049 \\
\hline
\end{tabular}

Between 8 p.m. and 8 a.m

${ }^{b}$ Global Deterioration Scale

${ }^{c}$ Cumulative Illness Rating Scale 
Table 3 Logistic regression analyses with delirium with hyperactive symptoms ( $n=22$ ) as outcome variable, unadjusted and multiadjusted, for all the listed covariates, for all 254 patients

\begin{tabular}{|c|c|c|c|c|c|c|}
\hline & \multicolumn{3}{|c|}{ Unadjusted } & \multicolumn{3}{|c|}{ Multiadjusted } \\
\hline & OR & $95 \% \mathrm{Cl}$ & $p$-value & OR & $95 \% \mathrm{Cl}$ & $p$-value \\
\hline Ward-transfers & 1.14 & 0.36 to 3.54 & 0.83 & 1.11 & 0.35 to 3.49 & 0.86 \\
\hline Arrive late ${ }^{a}$ & 0.74 & 0.21 to 2.60 & 0.63 & 0.41 & 0.10 to 1.62 & 0.20 \\
\hline Time spent in ED (hours) & 0.80 & 0.60 to 1.05 & 0.11 & 0.75 & 0.56 to 1.02 & 0.065 \\
\hline Investigations at nighttime ${ }^{a}$ & 1.67 & 0.68 to 4.09 & 0.26 & 2.00 & 0.77 to 5.16 & 0.15 \\
\hline
\end{tabular}

aetween 8 p.m. and 8 a.m

the associations between the other exposure variables and incident delirium. The lack of association between time spent in the ED and incident delirium might reflect that the ED in our hospital emphasises initial examination and short stay before transfer to a relevant ward, thereby providing less insult to vulnerable patients than the ED as described by Bo et al. [18]. Another explanation may be that physicians identify the patients prone to develop delirium as more vulnerable and examine these patients rapidly.

The lack of significant associations between any of the variables and delirium motor subtypes must be interpreted carefully due to a small number of observations. There is a trend towards less delirium with hyperactive symptoms with increasing time spent in the ED, which is plausible since the staff in ED might register signs of hyperactivity and therefore transfer these patients fast. An alternative hypothesis is that too quick transfers could be stressful and thereby inducing delirium. It remains uncertain if this trend would have reached statistical significance if the study was designed for this purpose. The results of previous studies addressing the relation between motor subtypes and etiology are diverging.
A recent cross-sectional study found a negative association between use of atypical antipsychotics and hypoactive delirium and a positive association between intravenous lines and mixed delirium [11], possibly indicating differences in etiology between the subtypes. On the other hand, two reports from a longitudinal study designed to investigate the relationship between motor subtypes and other factors found no associations between motor subtypes and etiology [8], age and preexisting dementia [10]. Our results complies with the two latter reports.

\section{Strengths and limitations}

The major strength of this study is that we have diagnosed delirium using the DSM-5 criteria directly and based the diagnoses on a combination of interviews with patients, nurses and proxies and a validated chart review method. The completeness of all variables of interest is another strength. The major limitation is the small number of patients with incident delirium. The limited sample size is particularly important when it comes to the analyses of environmental factors and delirium motor

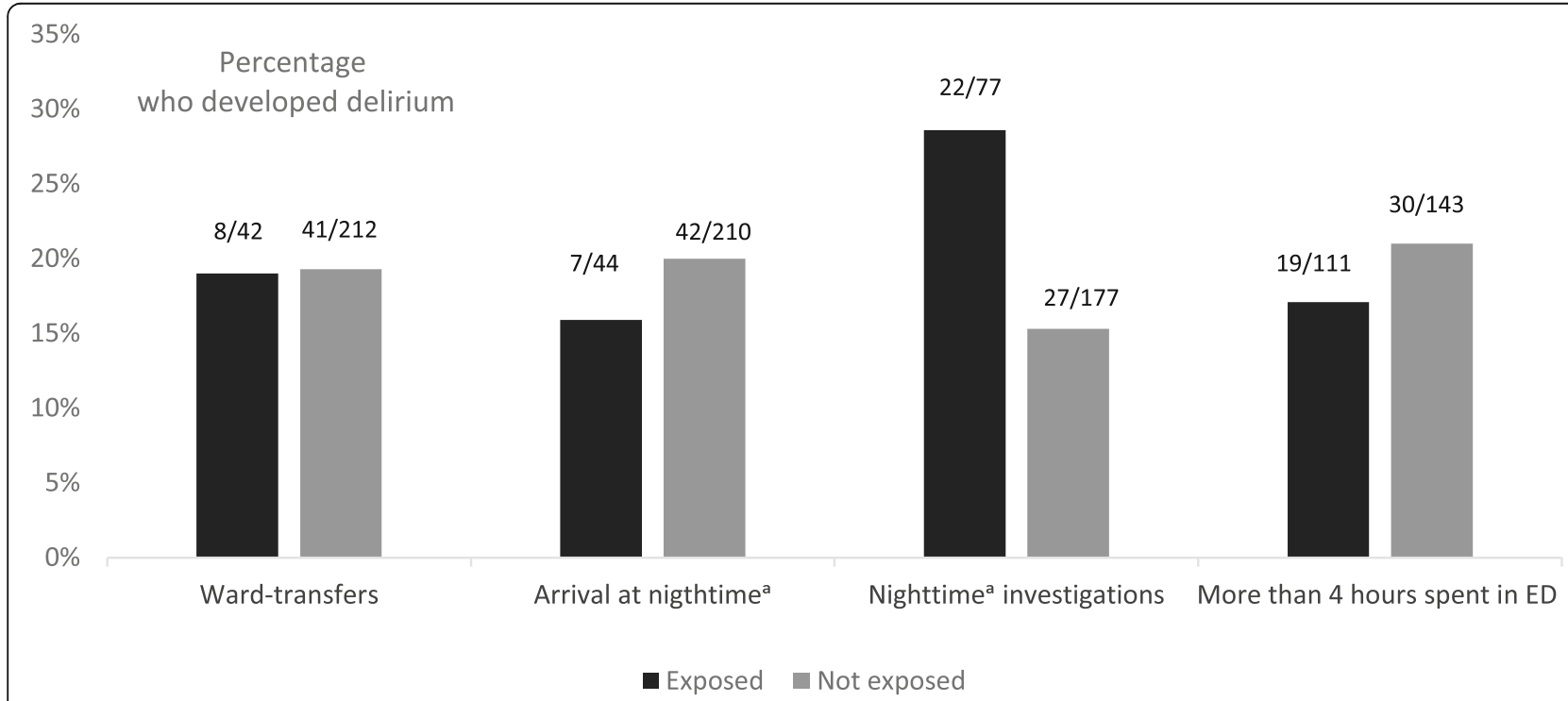

Fig. 2 Percentages of patients who developed delirium among those who were exposed (black bars) and unexposed (grey bars) to the environmental factors. ${ }^{a}$ Between 8 p.m. and 8 a.m 
subtypes. Uncertainty about what is triggering delirium could have been reduced if we had reliable diagnoses for admissions to both hospital and nighttime investigations, and lack of such information is a limitation. A further limitation is that we were not strictly blinded to the exposure of environmental factors when diagnosing delirium, but we believe this has minor implications since we were focusing the presence of physiological disturbance resulting in delirium. Finally, our findings are not necessarily generalizable to non-geriatric wards and younger patients, or to EDs organized in a different way than in our hospital.

\section{Conclusions}

In this observational study on 254 acutely admitted geriatric patients we found an association between nighttime investigations and incident delirium, but no associations between any of the exposure variables and delirium motor subtypes. In general, investigations should therefore be done in a predictable way at daytime, althoug patients should have emergency investigations at nighttime when indicated. Hospital environment in broad sense may be a target for delirium prevention along with nonpharmacological delirium intervention programs. There is a need for larger studies with both accurate registrations of environmental factors and a precise diagnostic work-up of delirium.

\section{Abbreviations \\ APACHE: Acute Physiology And Chronic Health Evaluation; BI: Barthel Index; Cl: Confidence Interval; CIRS: Cumulative IIIness Rating Scale; DMSS: Delirium Motor Subtype Scale; DSM: Diagnostic and Statistical Manual of Mental Disorders; ED: Emergency Department; GDS: Global Deterioration Scale; OR: Odds Ratio; SD: Standard Deviations; SPPB: Short Physical Performance Battery}

\section{Acknowledgements}

Warm thanks to the staff at the geriatric ward for help with inclusion of patients and data collection.

\section{Funding}

The Liaison Committee for education, research and innovation in Central Norway funded the project. We confirm that the funder had no role in designing the study, in the collection, analyses or interpretation of data or in writing/ submitting the manuscript.

\section{Availability of data and materials}

Datasets from this study are not available since we do not have the consent to share the data neither from The Regional Committee for Medical and Health Research Ethics nor from the patients.

\section{Authors' contributions}

SE did the initial drafting of the article, had the main responsibility for data collection and for diagnosing and subtyping delirium. IS participated in designing and planning the study with particular responsibility in data collection at the geriatric ward. SL had the main responsibility for the statistical analyses. TBW participated in designing and planning the study with particular responsibility in the diagnostic work-up of delirium and subtyping. KT participated in designing and planning the study. OS is the project manager and designed the study. He also participated in diagnosing and subtyping of delirium. All authors have critically read and approved the final manuscript.

\section{Ethics approval and consent to participate}

We confirm that all patients or a proxy consented for participation based on the concept of written informed consent. The Regional Committee for Medical and Health Research Ethics of Mid-Norway approved the study (REK Central 2015/474)

\section{Consent for publication}

Not applicable.

\section{Competing interests}

The authors declare that they have no competing interests.

\section{Publisher's Note}

Springer Nature remains neutral with regard to jurisdictional claims in published maps and institutional affiliations.

\section{Author details}

${ }^{1}$ Department of Geriatrics, St. Olavs hospital, Trondheim University Hospital, Trondheim, Norway. ${ }^{2}$ Department of Neuromedicine and Movement Science, Faculty of Medicine and Health Sciences, Norwegian University of Science and Technology (NTNU), N-7491 Trondheim, Norway. ${ }^{3}$ Regional Centre for Child and Youth Mental Health and Child Welfare, NTNU, Norwegian University of Science and Technology, Trondheim, Norway. ${ }^{4}$ Oslo Delirium Research Group, Department of Geriatric Medicine, Oslo University Hospital, Oslo, Norway. ${ }^{5}$ Institute of Clinical Medicine, University of Oslo, Oslo, Norway.

Received: 21 June 2018 Accepted: 6 November 2018

Published online: 15 November 2018

\section{References}

1. Marcantonio ER. Delirium in hospitalized older adults. N Engl J Med. 2017; 377(15):1456-66.

2. Inouye SK, Westendorp RG, Saczynski JS. Delirium in elderly people. Lancet. 2014;383(9920):911-22.

3. Witlox J, Eurelings LS, de Jonghe JF, Kalisvaart KJ, Eikelenboom P, van Gool WA. Delirium in elderly patients and the risk of postdischarge mortality, institutionalization, and dementia: a meta-analysis. JAMA. 2010;304(4): $443-51$

4. Oh ES, Fong $T G$, Hshieh $T$, Inouye SK. Delirium in older persons: advances in diagnosis and treatment. JAMA. 2017;318(12):1161-74.

5. Liptzin B, Levkoff SE. An empirical study of delirium subtypes. Br J Psychiatry. 1992;161:843-5.

6. Bellelli G, Speciale S, Barisione E, Trabucchi M. Delirium subtypes and 1-year mortality among elderly patients discharged from a post-acute rehabilitation facility. J Gerontol A Biol Sci Med Sci. 2007;62(10):1182-3.

7. Kiely DK, Jones RN, Bergmann MA, Marcantonio ER. Association between psychomotor activity delirium subtypes and mortality among newly admitted post-acute facility patients. J Gerontol A Biol Sci Med Sci. 2007; 62(2):174-9

8. Meagher DJ, Leonard M, Donnelly S, Conroy M, Adamis D, Trzepacz PT. A longitudinal study of motor subtypes in delirium: relationship with other phenomenology, etiology, medication exposure and prognosis. J Psychosom Res. 2011;71(6):395-403.

9. Yang FM, Marcantonio ER, Inouye SK, Kiely DK, Rudolph JL, Fearing MA, Jones RN. Phenomenological subtypes of delirium in older persons: patterns, prevalence, and prognosis. Psychosomatics. 2009;50(3):248-54.

10. Meagher DJ, Leonard M, Donnelly S, Conroy M, Adamis D, Trzepacz PT. A longitudinal study of motor subtypes in delirium: frequency and stability during episodes. J Psychosom Res. 2012;72(3):236-41.

11. Morandi A, Di Santo SG, Cherubini A, Mossello E, Meagher D, Mazzone A, Bianchetti A, Ferrara N, Ferrari A, Musicco M, et al. Clinical features associated with delirium motor subtypes in older inpatients: results of a multicenter study. Am J Geriatr Psychiatry. 2017;25(10):1064-71.

12. Association AP. DSM-5 classification. Washington: American Psychiatric Publishing; 2013.

13. Hshieh TT, Yue J, Oh E, Puelle M, Dowal S, Travison T, Inouye SK. Effectiveness of multicomponent nonpharmacological delirium interventions: a metaanalysis. JAMA Intern Med. 2015;175(4):512-20.

14. Inouye SK, Bogardus ST Jr, Charpentier PA, Leo-Summers L, Acampora D, Holford TR, Cooney LM Jr. A multicomponent intervention to prevent delirium in hospitalized older patients. N Engl J Med. 1999;340(9):669-76. 
15. McCusker J, Cole M, Abrahamowicz M, Han L, Podoba JE, Ramman-Haddad L. Environmental risk factors for delirium in hospitalized older people. J Am Geriatr Soc. 2001;49(10):1327-34.

16. Beresin EV. Delirium in the elderly. J Geriatr Psychiatry Neurol. 1988;1(3):127-43.

17. Goldberg A, Straus SE, Hamid JS, Wong CL. Room transfers and the risk of delirium incidence amongst hospitalized elderly medical patients: a case-control study. BMC Geriatr. 2015;15:69.

18. Bo M, Bonetto M, Bottignole G, Porrino P, Coppo E, Tibaldi M, Ceci G, Raspo S, Cappa G, Bellelli G. Length of stay in the emergency department and occurrence of delirium in older medical patients. J Am Geriatr Soc. 2016; 64(5):1114-9.

19. Maclullich AM, Ferguson K, Miller T, de Rooij SE, Cunningham C. Unravelling the pathophysiology of delirium: a focus on the role of aberrant stress responses. J Psychosom Res. 2008;65(3):229-38.

20. Carpenter CR, Bromley M, Caterino JM, Chun A, Gerson LW, Greenspan J, Hwang U, John DP, Lyons WL, Platts-Mills TF, et al. Optimal older adult emergency care: introducing multidisciplinary geriatric emergency department guidelines from the American College of Emergency Physicians, American Geriatrics Society, emergency nurses association, and Society for Academic Emergency Medicine. J Am Geriatr Soc. 2014;62(7):1360-3.

21. Ellis G, Gardner M, Tsiachristas A, Langhorne P, Burke O, Harwood RH, Conroy SP, Kircher T, Somme D, Saltvedt I, et al. Comprehensive geriatric assessment for older adults admitted to hospital. Cochrane Database Syst Rev. 2017:9:CD006211.

22. Evensen S, Sletvold O, Lydersen S, Taraldsen K. Physical activity among hospitalized older adults - an observational study. BMC Geriatr. 2017:17(1):110

23. Hall RJ, Meagher DJ, MacLullich AM. Delirium detection and monitoring outside the ICU. Best Pract Res Clin Anaesthesiol. 2012;26(3):367-83.

24. Folstein MF, Folstein SE, McHugh PR. "Mini-mental state". A practical method for grading the cognitive state of patients for the clinician. J Psychiatr Res. 1975;12(3):189-98.

25. Inouye SK, Leo-Summers L, Zhang Y, Bogardus ST Jr, Leslie DL, Agostini JV. A chart-based method for identification of delirium: validation compared with interviewer ratings using the confusion assessment method. J Am Geriatr Soc. 2005;53(2):312-8.

26. Saczynski JS, Kosar CM, Xu G, Puelle MR, Schmitt E, Jones RN, Marcantonio ER, Wong B, Isaza I, Inouye SK. A tale of two methods: chart and interview methods for identifying delirium. J Am Geriatr Soc. 2014;62(3):518-24.

27. Meagher D, Moran M, Raju B, Leonard M, Donnelly S, Saunders J, Trzepacz P. A new data-based motor subtype schema for delirium. J Neuropsychiatry Clin Neurosci. 2008;20(2):185-93.

28. Reisberg B, Ferris SH, de Leon MJ, Crook T. The global deterioration scale for assessment of primary degenerative dementia. Am J Psychiatry. 1982; 139(9):1136-9

29. Salvi F, Miller MD, Grilli A, Giorgi R, Towers AL, Morichi V, Spazzafumo L, Mancinelli L, Espinosa E, Rappelli A, et al. A manual of guidelines to score the modified cumulative illness rating scale and its validation in acute hospitalized elderly patients. J Am Geriatr Soc. 2008;56(10):1926-31.

30. Mahoney Fl, Barthel DW. Functional evaluation: the Barthel index. Md State Med J. 1965:14:61-5.

31. Guralnik JM, Simonsick EM, Ferrucci L, Glynn RJ, Berkman LF, Blazer DG, Scherr PA, Wallace RB. A short physical performance battery assessing lower extremity function: association with self-reported disability and prediction of mortality and nursing home admission. J Gerontol. 1994;49(2):M85-94.

32. Knaus WA, Draper EA, Wagner DP, Zimmerman JE. APACHE II: a severity of disease classification system. Crit Care Med. 1985;13(10):818-29.

33. Siddiqi N, Harrison JK, Clegg A, Teale EA, Young J, Taylor J, Simpkins SA. Interventions for preventing delirium in hospitalised non-ICU patients. Cochrane Database Syst Rev. 2016;3:CD005563.

Ready to submit your research? Choose BMC and benefit from:

- fast, convenient online submission

- thorough peer review by experienced researchers in your field

- rapid publication on acceptance

- support for research data, including large and complex data types

- gold Open Access which fosters wider collaboration and increased citations

- maximum visibility for your research: over $100 \mathrm{M}$ website views per year

At BMC, research is always in progress.

Learn more biomedcentral.com/submissions 